\title{
The influencing potential of the conflictogenic media space in the aspect of legal culture
}

\author{
Tatiana Rogozhnikova ${ }^{1 *}$ and Elvina Salikhova ${ }^{2}$ \\ ${ }^{1}$ Ufa State Aviation Technical University, 12, Karl Marx St., Ufa, 4500008, Bashkortostan, Russia, burzian@yandex.ru \\ ${ }^{2}$ Ufa State Aviation Technical University, 12, Karl Marx St., Ufa, 4500008, Bashkortostan, Russia, salelah12@yandex.ru
}

\begin{abstract}
The authors consider the problematic field of conflictogenic media space in a linguisticlegal aspect. The goal of the article is to present the individual results of linguistic and psycholinguistic studies of polycode controversial texts. In expert practice the authors actively employ the emotional-lexical assessment of verbal and non-verbal models, the assessment of the rhythmic brain activity during the perception of the entire text, the assessment of the rhythmic coherence in the perception of individual parts of the text and their comparison, the technique for recognizing the hidden motives of the object behavior in the process of its professional activity, analysis of the individual coefficients of the text impact on the individual and mass consciousness and subconsciousness. Conflict genes are demonstrated and described in this work. These are the minimum significant units of the component of the conflictogenic media space. The specific character of the polycode text, the texture of which consists of verbal and non-verbal parts, is demonstrated. The quantitative and qualitative results of the research performed are determined by the potential of classical linguistics and related branches of knowledge for solving polycode text problems using the developed software products in the field of psycholinguistic investigations.
\end{abstract}

\section{Introduction}

From an expert and analytical point of view, the conflictogenic zone of the modern media space is considered by us 1) as a fragment of the socio-discursive field, which reflects the "communicative battles and fights" taking place in it, whose participants (journalistsauthors of publications, including "commissioned" ones, and their heroes), being subjects of the network sociocultural system, violate the norms of speech behavior and subsequently act as plaintiffs / defendants in litigations (for example, for the protection of honor, dignity and business reputation - art. 152 of the Civil Code of the Russian Federation or for slander and insult - art. 129, 130 of the Criminal Code of the Russian Federation); 2) as a linguo-ecological environment that has a public character, the signs of which are identified by experts in the published information - in the disputed text (see, in particular, art. 128.1 of the Criminal Code of the Russian Federation). A journalist cannot fail to reflect the dynamics of a society that is closely linked to the development of economic, socio-political relations and innovations. The media play a special role in this process and are able to have a significant impact on one or another object of their attention, on the evaluative attitude of society to this object, on its reputation, etc.

1.1 Linguistic and psycholinguistic expertise (hereinafter referred to as LE and PLE) is based in conjunction on the appropriate scientific and methodological tools and terminological subsystems. In contrast to the linguistic, psychological-linguistic and psychological types of expertise, the PLE is based on specific data from experimental linguistics, which studies the products of human speech activity based on experimental materials. Successful results of the formalization of these psycholinguistic (PL) experiments in the form of computer programs have increased the possibilities of using this scientific paradigm in judicial linguo-expert activity. Creating a visualized result of the processed data, based on statistics, on the comparison of coupled databases, enriches the expertise and eliminates the subjective interpretation of the speech product.

1.2 One of the functions of human speech, as well as any text, is the function of influence. Within the framework of the PL, methods have been developed and units of analysis have been identified, with the help of which it is possible to give an objective evaluation of the material: to measure in quantitative terms the strength of the impact of the text, to establish the quality of this impact, to decode the suggestive potential of the language phenomenon, to rank emotional and evaluative signs, to evaluate the motives and intentions of the author of the text, to calculate the "golden section" of the text as a zone of uncontrolled influence on consciousness. The expert uses special units of analysis in order to study the latent suggestive resources of the text, since the lack of linguistic manifestations of deep internal forms does not lend itself to analysis through

\footnotetext{
* Corresponding author: burzian@yandex.ru
} 
traditional linguistic and psychological techniques and methods. The figures (see Figures 1-8) show examples of the results of working with such analytical units. Explanations of the illustrations are given below in the relevant sections of the article.

Fig. 1. The brain waves pattern activated by the Painter's comments perception in connection with the "KruShchu..." caricature publishing

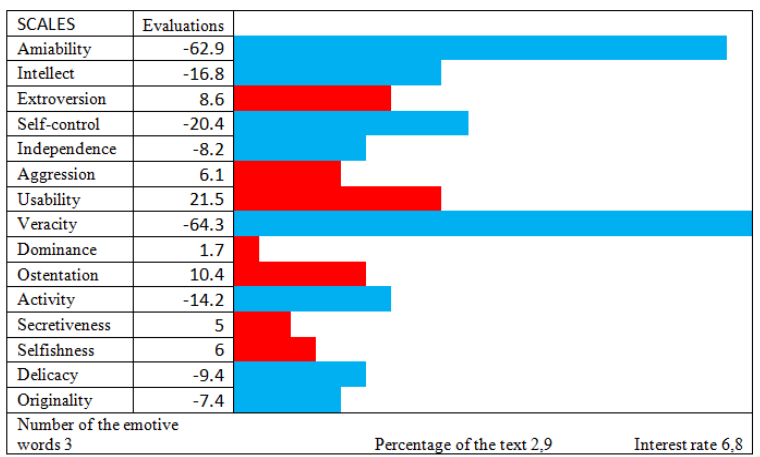

Fig. 2. The emotional-lexical evaluations of the «Pontius Pilatus» caricature, writings and comments

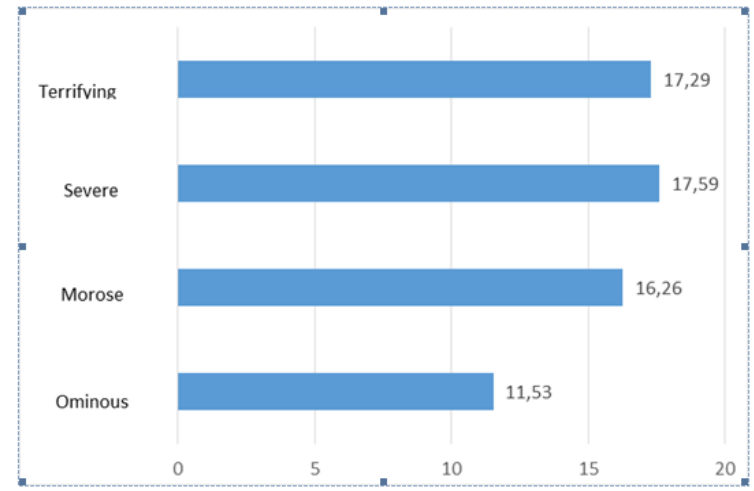

Fig. 3. The dominant features of the «Pontius Pilatus» caricature

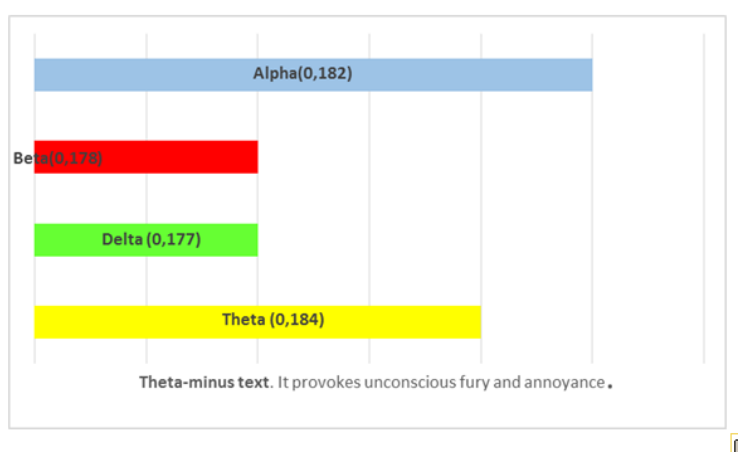

Fig. 4. The brain waves patterns activated by the perception of all the caricature writings analyzed

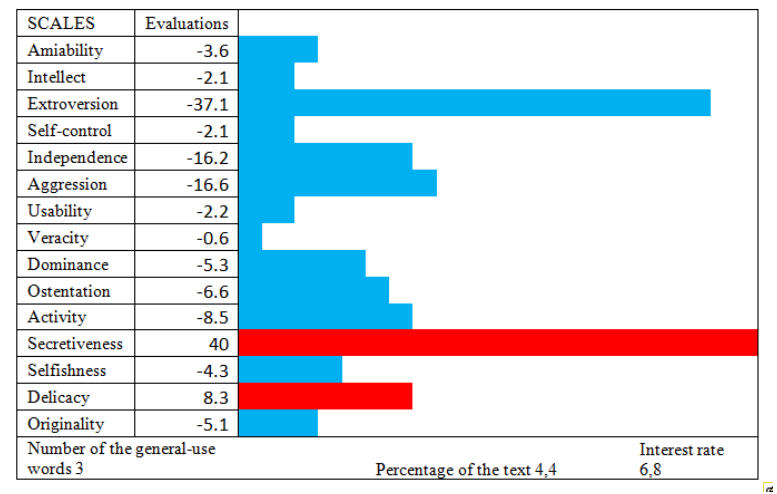

Fig. 5. The emotional-lexical evaluations of the caricature writings

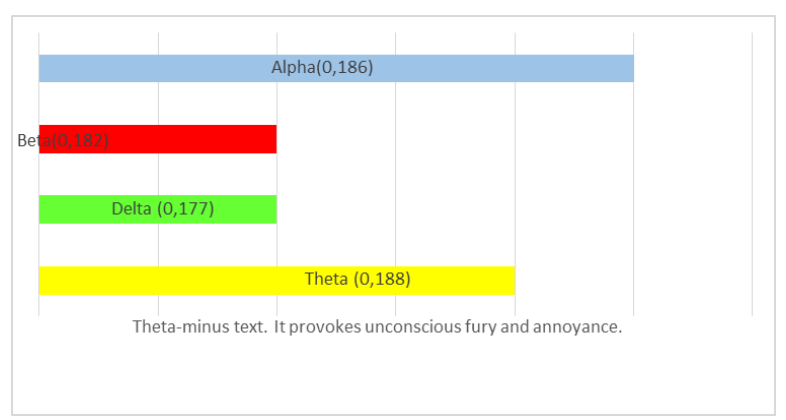

Fig. 6. The brain waves pattern activated by the perception of the «Have a lick» caricature writings

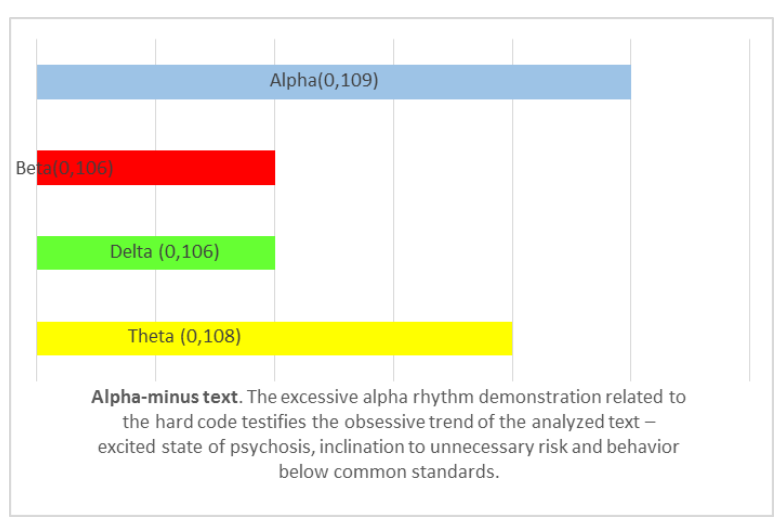

Fig. 7. The brain waves pattern activated by the «Have a lick» caricature comments perception 


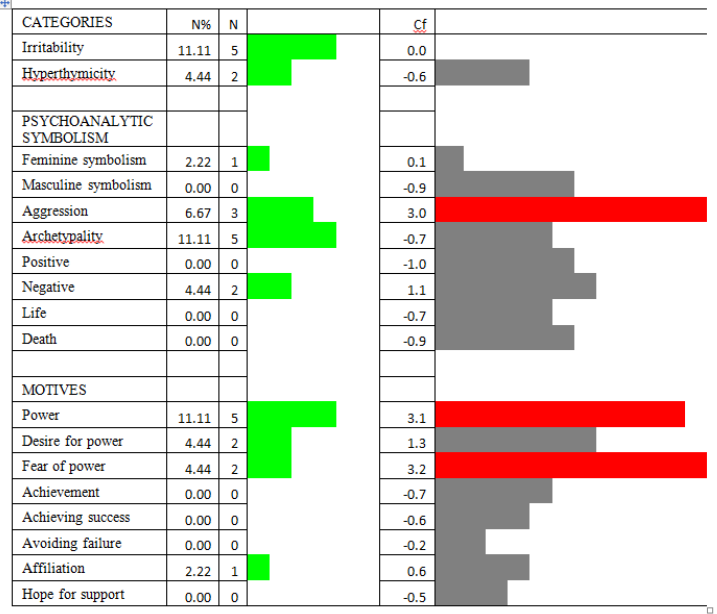

Fig. 8. The load on the categories (categorial-statistical evaluations) of the «Have a lick» caricature

\section{Problem Statement}

Traditionally, linguists conduct a study of the text in order to identify its semantic orientation, the expressiveness of speech units, the modality of propositions, their semantics and formal-grammatical characteristics, the specifics of the stylistic means used. Psycholinguists identify those conflictogens through which it is possible to decode the influencing potential of a language phenomenon. In order for lawyers to qualify cases of information distortion, linguists and psycholinguists should be able to differentiate communicative elements according to their purpose to provoke a conflict through separate linguistic elements sound-letter complexes, morphemes, words and their combinations, titles, utterances, intonation, video sequences, etc. [1].

Conflictogens, representing the minimum significant units of the discursive component of the media space, act as detonators of a conflict communicative situation. The origins of the latter, as shown by the long-term expert practice of the authors of the article, indicate personal motives that encourage the author (whether a journalist, commentator of remarks in social network chats or a participant in discussions) to inform the public.

\section{Research Questions}

Within the framework of the publication, we propose one of the ways to understand complex LE and PLE based on the achievements of modern Russian applied linguistics and PL. As illustrations, fragments of a comprehensive expertise with the participation of the authors of the article are provided (with the preservation of confidentiality and the symbol of the subjects - the Artist, the Organization, the Head of the Organization). In a modern society characterized by information saturation, there is an increasing need to rank the information flow in such a way already at the stage of text generation, so that the addressee can effectively isolate the most significant information for himself. This is expressed in semiotically complicated (polycode, creolized) texts that include verbal and nonverbal components. In the modern media space, such a synthesis of the word and the iconic element is presented in written and oral texts of journalistic communication.

The term "creolized texts" is widely known, which is used in psycholinguistics by Yu. A. A. Sorokin and E. F. Tarasov. In their opinion, these are " texts whose texture consists of two inhomogeneous parts (verbal language (speech) and non-verbal (belonging to other sign systems than natural language)" [2]. As a working, this term is used in their works by E. E. Anisimova, M. A. Boyko, N. S. Valgina, N. M. Chudakova, M. B. Shinkarenkova and others. The researchers note that the creolized text appears as a complex text formation, in which verbal and non-verbal elements form one visual, structural, semantic and functional whole, aimed at a complex impact on the addressee. Further development of research in this area has shown that the terminological value of the concept of "creolized text" has become a subject for further discussion [3]

So, semiotically heterogeneous or complicated phenomena are treated in science as polycode (A. V. Alferov, G. V. Eiger, A. G. Sonin, V. L. Yukht), as creolized (E. E. Anisimova, Yu. A. Sorokin, E. F. Tarasov), as isoverbal (A. A. Bernatskaya), as videoverbal (O. V. Poymanova), as heterogeneous (M. A. Ishchuk, A. G. Sonin), as linguovisual (L. M. Bolshiyanova), as a kommunikat (N. N. Volskaya, V. E. Chernyavskaya), as visual (A. A. Kornienko). Under the term "polycode" text (identical in meaning in this article, the term "creolized" is used) we, following A. G. Sonin [4], T F. Petrenko [5], Z. I. Trubina [6], understand a multi-level sign formation of a synthetic nature, which represents unity in functional-structural, semantic and communicative aspects and which is built on the combination of semiotically heterogeneous components. A person who perceives video or audio information pays attention to alphabetic and other sign means and interprets them in the intentional direction set by the author of the text. The creolized text, which is the object of our research, is the text that accompanies the "static" caricatures on the pages of the social networks "Facebook " and "Instagram". In them, the Artist is the author of graphic conflictogenic works and part of the printed texts expresses his critical attitude to the situation that has developed around a well-known Organization in Bashkiria. The studied discourse environment has a focus on visual perception (text and graphic materials); spatial and temporal extension, pictorial character, continuity; a special sphere of functioning (assessed in perception as a socially significant activity).

\section{Purpose of the Study}

The set of visual materials with text comments of the participants-visitors of the page forms the syntactic hierarchy of the Internet page, which is built depending on the features of the perception of the sign, on the degree of unambiguity and objectivity of its interpretation. With this approach, symbols, mainly graphic and linguistic together, are organizing the text 
space as a whole. This function is performed by the verbal title of the material, rarely in the format of a chat in a social network, made out with the help of graphic or numeric characters. In the context of communication in a social network, both the title and the author's comment spatially frame the video sequence and accompany the text, minimizing possible interpretations of the text.

In the linguosemiotic and PL aspects, the caricature of the Head of the Organization in the form of a thimblerigger has a tough complex effect. Caricature (from caricare "exaggerate") - a satirical or humorous image in which the comic effect is created by exaggerating unpleasant features, unexpected likenesses. When analyzing this polycode text, there were no signs of a comic effect. The characteristic signs of the text were sinister, gloomy, harsh, and intimidating. They create negative images not only of the Head of the Organization and members of the community, but also of such structures as the court, the prosecutor's office, the Ministry of Internal Affairs, which the main character manipulates as a gambler-a thimblerigger. Linguistic synonyms of the concept - a fraudster, a swindler ("A swindler with a tailor's tool"; "a fraudster who speaks: "I twist and turn, I want to confuse everything!"" [7], the deceiver [8] - leave no doubt that the use of this image in public communication humiliates the honor and dignity of a particular person, as well as harms the business reputation of these structures, lowers their status [9], making them the subject of condemnation by society.

The caricature, as well as the inscriptions to it, have a hard complex effect on the subconscious of those who read and consider it. The sound side of the inscriptions and comments on the caricatures also adds stiffness. Variants of the pronunciation of the words Krushchu (from the distorted sound appearance of the verb "twist" - "1. To bring in a circular, rotational movement; to rotate, to turn. 7. Conv. To dispose of at your own discretion, to command. 8 conv. To avoid a direct answer with any tricks, trickery" [8]; the same VERSCHU from the verb "to spin" - "3. Conv. to dispose at your own discretion, to force to act at your own will" [ibid. P. 120]; KHOSHCHU from "to want" "1. To have a desire, an intention to do something; to feel the need, the need for someone/something" [ibid. P. 1452], "to confuse" - "2. To make it unclear, difficult to understand, or complicated. 3. Conv. To confuse, to mislead. 4 Conv. To involve someone in any unpleasant business, to implicate" [ibid. P. 341]"), Verschu, Khashchu exaggeratedly demonstrate the accent inherent in the Turkic-speaking native speakers of the Russian language. Such examples are numerous and can be found both in other caricatures (Gumerysch, Zaoschnik) and in the comments to them (molodiS, Razdascha, do konSa). Re-checking the conclusion about the harsh complex impact of this image, accompanied by inscriptions, was carried out by us through the analysis of the Artist's comments, with which he accompanied an open discussion about the caricature on social networks. Figure 1 shows the patterns of brain waves occurred during such a "conversation" with different commentators.
4.1 The excessive manifestation of the alpha-minus rhythm, associated with hard coding and hard impact, again indicates the manic orientation of the speech product generated by the Artist, which can lead him and those he affects to unnecessary risk and violation of the rules of behavior, including speech. A high rate of betaminus rhythm acts as a provocateur of excitement, fear and anxiety, always introduces a stressful destabilizing component both in communication and in the situations that accompany it [10].

4.2 According to the classification of invective vocabulary in [11], the word fraudster, which is strongly associated with the image of a thimblerigger, belongs to the first group of "words and expressions that conceptually denote antisocial, socially (and more often legally) condemned activities". It is noted that the use of such units in the sphere of public and formalized public communication is considered an insult, that is, it is a question of such a nature of the context, "which can infringe on the honor, detract from the dignity and harm the reputation of the characterized persons, if the facts stated in the justification of the assessments are fictitious" (ibid. Pp. 209-210). The targeting of the public use of invective lowers the public status of the depicted subject, gives it the status of a socially condemned person, putting it in the role of the guilty [12]; reveals, makes publicly known the personal hostility of the addressee, ... makes the victim the subject of discussion in society, the subject of gloating. The information in the comments and descriptions of the situation around the Organization is given in the form of statements about the facts of the condemned character's activities and actions in a managerial position, which are condemned by society as illegal and immoral. Such information is aimed at humiliating the dignity of a citizen, but does not have an indecent (obscene) form, although it can significantly discredit the honor, dignity and business reputation of a particular criticized person. As E. S. Kara-Murza clarifies, "from the linguistic and legal point of view, defamatory information, first, is information about the offenses or misdemeanors (of the plaintiff), and not any negative factual information about him. Secondly, it concerns directly (the plaintiff). Thirdly, it should be expressed in the form of a statement" [13].

4.3 The interpretation of the caricature, conditionally called by us "Pontius Pilate...", is also quite transparent for the reader's perception. An artist who works in such a genre is always in a conflictogenic risk zone, because it is associated with a potential insult. The caricature, being anonymous in different epochs, has now finally lost it and has gained not only a specific goal for psychological attack, but also a certain number of supporters, on whose opinion the caricaturist relies. There was a transition to personality, which means a new type of functioning of the insult. The time has come for a march, clothed in an artistic form, on human dignity itself, regardless of the place in society of the Artist and his victim. The dialogue, which is conducted in the language of "artistic insults" [14], does not lead to the establishment of truth or reconciliation. The purpose of this kind of creativity is to arouse the determination of the opposition, morally 
eliminate, weaken and humiliate the enemy. The possible political bias of the work is based on the totality of the values of the social group on behalf of which the Artist acts. And here there is a question about the ethical limits of what is permissible, which explicates and makes clear the author's (Artist's) own ideas about aesthetics and morality.

In the context of the promoted attitude to the Head of the Organization on the Internet page, the interpretation is unambiguous - he carries his cross associated with guilt and death. The cynicism of caricature positions the Artist as a person who does not know the measure of what is allowed, who descends to mockery and is not able to stop at the line that cannot be crossed. This leads to the fact that the character, in accordance with the laws of associative processes, becomes a martyr, and the depicted judge (a well - known political strategist in Ufa) is a villain who has assumed the role of a prosecutor.

Figure 2 shows the results of the emotional-lexical evaluation. Recall that the special PL block of the computer program VAAL [15] takes into account not only evaluative words, but also adjectives, verbs and nominalizations used to describe and evaluate a person. As semantic scales, 15 factors are used, according to which each lexical unit is evaluated, and the emotional background is determined by the evaluations of the participants of the experiments, their expectations and experiences. Analyzing the material on the factors of emotional evaluation, the specialist has the opportunity to establish the main criteria and values for them. Emotional-lexical evaluations are calculated by calculating the average values for each of the scales. If the resulting evaluation is positive, the histogram line is red, if it is negative, it is blue. At the bottom of the histogram, data on the number of emotional-evaluative words in the text, the percentage of emotional-evaluative words from all the words of the analyzed text, as well as the normal percentage of emotional-evaluative words in the Russian language are shown.

The perception of this text material is characterized by extremely high evaluation coefficients: the emotional state of the Artist is assessed as unfriendly (62.9), untruthful (64.3); there is no self-control (20.4) and the independence of the author (8.2). If self-control is a person's inherent ability to control their own behavior, based on the will as the highest mental function responsible for conscious decisions, then the lack of independence indirectly indicates the artist's bias. You should pay attention to the indicators of aggressiveness (6.1) and demonstrativeness (10.4), which are colored in red in Figure 2. Verbal or pictorial aggressiveness is a form of activity aimed at insulting and / or causing harm to another; demonstrativeness is a trait of hysterical personalities, manifested in emotionally colored behavior through the desire to be visible and the desire to please (see the Artist's comments: I want to continue to respect you all; I do not condemn; I enter the situation))); well, that's nice). This type of people is prone to deliberate exaggerations, designed for external effect and expressiveness of manifestations. Through caricature as a detailed drawing and deliberate sharpening of some traits and features, there are signs of demonstrativeness as a psychological characteristic of the author's personality.

4.4 This caricature, as well as the inscriptions to it, like all other works of the Artist, is devoid of a humorous component, which is manifested in PLE through the dominant characteristic features: intimidating (coefficient-17.59); severe (17.29); gloomy (16.26); sinister (11.53). Figure 3 shows the signs of the polycode product "Pontius Pilate...". Caricatures with a missing humorous component become a destructive product of settling scores and have a great offensive potential.

To double-check the validity of the results of this aspect of the analysis, the experts examined the characteristic features of the inscriptions accompanying the caricature "Pontius Pilate..." (the orthography and style of the original are preserved): Dui, Bulat Gumerysh, on his Golgof. And here's your Pontius Pilate. If, of course, you understand what I'm talking about and who I'm talking about, zaoschnik hrenov))))). Apparently, the author intuitively realizes that the figure does not cause smiles. This can explain the presence of five (!) signs-brackets that replace the smile after the inscription, and probably mean homeric laughter. Only, alas, the author himself, not the readers. The characteristics of the above inscription for the presence of a humorous component include: frightening (5.89); dark (5.65); sinister (5.61); sad (4.82); gloomy (4.21); severe (4.09); heavy (2.69); dreary (1.52). The results of a comprehensive analysis of the available inscriptions on the caricatures provided for analysis are shown in the following figure (Figure 4).

Excessive manifestation of theta-minus rhythms leads to a state of irritation and anger. It is theta waves that are ideal for non-critical acceptance of various external attitudes and beliefs that change the attitude towards others and shape the corresponding behavior. These rhythms are responsible for reducing the protective mental mechanisms that allow critical evaluation of information. These rhythms allow transformative information to penetrate deep into the subconscious (These states are used in hypnosis. See: Cherepanova [16]. It is important to emphasize that with the activation of such a pattern, critical comprehension of the perceived is lost, but emotional experiences increase. Figure 5 shows the emotional and lexical evaluations of all the caricature inscriptions. Note that the text space is characterized by ill will $(-3.6$, blue zone), dependence (- 16.2), and lack of self-control (2.1).

The result, associated with the author's style, is characterized by the desire for refinement and sophistication of the works. The revealed refinement coefficient (+8.3, red zone) makes the Artist a recognizable author with his own individual handwriting. The calculations of the dominant characteristic signs revealed in the analysis of all the inscriptions on all the caricatures are as follows: frightening - 11.37, sad - 11.01. They are considered dominant because their coefficients go beyond the sign registered as available in the product. The analysis of all 
the signs revealed the following: dark (8.38), dreary (4.8), minor (3.47), heavy (1.84), sinister (0.16), gloomy (0.01).

4.5 In the final caricature series, the climactic image of the character unbuttoning his belt and taking off his trousers at the request of members of the criticized community (The people ask, how can you refuse ...), in order to bare his ass for them (To lick is the right of a lawyer, Chief, do not hesitate! We are for!!!, We lick the whole chamber - as one!) this image is intended to give a negative characterization of both the Organization as a whole, "bending" under its head, and its Head. Visual symbols and their verbal description are made in an obscene form with a gross violation of the norms accepted in society and with a violation of thematic communicative taboos that affect topics that are morally prohibited for public discussion (physiological processes, sexual actions, various kinds of perversions). Figures 6 and 7 show the patterns of brain activity that are activated when a given polycode text is perceived.

The quality of the impact of the speech product is determined by us through the establishment of the dominant rhythm in the pattern of brain activity. With the help of the new version of the computer program DIATON [17], it is possible to analyze 11 main states of brain rhythms and emotions related to it. For the convenience of describing the results of the analysis, each type of brain waves is assigned the signs "+"(plus) or "-"(minus), depending on the redundancy or insufficiency of the manifestations of one or another rhythm, the neutral position is fixed, the position of full synchronization of potentials with the sign "+"(coherence of waves) and the position of hard negative impact with the sign "-" (incoherence of waves). The predominance of a certain rhythm, revealed when working with a stimulus, means that the perception of this stimulus contributes to the emergence of one or another emotional state associated with this pronounced rhythm. So, analyzing the text through the prism of the brain waves that arise during its perception, we can judge the quality of the impact on a person. The polycode text, which includes the caricature inscriptions, as seen in Figure 6, causes an increase in theta-minus rhythms, accompanied by unconscious anger and irritation.

The rhythmic activity that occurs during the analysis of comments indicates that the image leads to the generation of speech products characterized by a manic orientation. Figure 7 shows a pattern of brain activity with a predominance of alpha-minus rhythm. With a high degree of probability, it can be assumed that the image entails not only negative consequences for the reputation of the Organization and a particular person its head, but also excites the audience states leading to possible violations of the norms of behavior.

Rechecking (using the VAAL expert system) of this conclusion through another aspect of the analysis related to the load on the categories showed the validity of the conclusion. A category is a set of tokens with a certain meaning. It is based on the frequency of use of words of the category as a whole and takes into account the indicator of the "normal" frequency of use of words by native speakers of this language. There are empirically defined norms for the use of various words. Knowing the "normal" frequency of this word in the Russian language, it is possible to calculate whether words of this category are used less often or more often by a particular person in a particular text. A category can be words that characterize a certain type of personality. Comparing with the norm the frequency of use of words of this category by a particular person, we can judge about his belonging to a certain psychotype. A category profile is a visual (in the form of a diagram) information about how words of different categories are distributed in the text.

Figure 8 shows the load indicators for the various categories; (1) the column names the category; (2) indicates the percentage of words in this category of the total text volume; (3) - the number of words of this category found in the analyzed text; (4) is a histogram of the visual representation of the quantitative characteristics of the distribution; (5) contains an estimate of the deviation of the number of words found in this category from the average language norm. This is the traditional evaluation of the $\mathrm{Z}$-score in content analysis, calculated by the formula: (N-E) / (standard deviation), where $\mathrm{N}$ is the number of words of this category found in the analyzed text, and $\mathrm{E}$ is the expected number of occurrences of words of this category in the text; the sixth column is a visual representation of the deviation of the number of words found in this category from the average language norm. The red color indicates a significant excess of the norm, the blue color indicates a significant deviation in the lower direction, and the gray color indicates an insignificant deviation from the norm either in the direction of its excess or in the lower direction.

In the category of "Psychoanalytic symbolism", a high level of aggressiveness was revealed. It is linked to the attraction to unnecessary risk and to the violation of norms of behavior.

\section{Research Methods}

We use a complex - linguistic and psycholinguistic approach to text analysis, which implies, in addition to the traditional practice of linguoexpertology, an appeal to statistical methods with tracing the hierarchy of frequency of verbal constructions and sound-letter complexes, with counting the number of identical models, with comparing the frequency of single sounds and with comparing the normative indicators of the frequency of use of certain sounds. We used factor, feature, semantic, content analysis of the text, analysis of the suggestive potential of the verbal model. In the expert practice of the authors, emotional and lexical evaluation of verbal and nonverbal models, evaluation of the rhythmic activity of the brain in the perception of the entire text, evaluation of the rhythmic coherence in the perception of individual parts of the text and their comparison, techniques for recognizing the hidden motives of the object's behavior in his professional activity, analysis of individual coefficients of the impact of the text on individual and mass consciousness and 
subconsciousness, evaluation of the impact of the polymodal text are also actively used.

The successful results of the formalization of these PL experiments in the form of computer programs allowed to increase the possibilities of using this scientific paradigm in judicial linguo-expert activity. The creation of a visualized result of the processed data, based on statistics, on the comparison of coupled databases, significantly enriches the expertise and eliminates the subjective interpretation of the speech product. One of the functions of human speech, as well as any written or oral text, is the phatic function, or the function of impact. Within the framework of the PL, methods have been developed and units of analysis have been identified, with the help of which it is possible to give an objective evaluation of the material: to measure in quantitative terms the strength of the impact of the text [18] to establish the quality of this impact, to decode the suggestive potential of a language phenomenon, to rank emotional and evaluative signs, to evaluate the motives and intentions of the author of the text, to calculate the "golden section" of the text as a zone of uncontrolled influence on consciousness [19].

The expert operates with special units of analysis in order to study the latent suggestive resources of the text, since the lack of linguistic manifestations of deep internal forms does not lend itself to analysis through traditional linguistic and psychological techniques and methods. On the basis of the Department of Language Communication and Psycholinguistics of UGATU, computer programs have been developed and successfully tested, with the help of which it is possible to work in five languages (Russian, English, German, Tatar and Bashkir): 1) Computer program BARIN (Automated analysis of words and text). Certificate of state registration of the computer program No. 2011618299 (M. 2011); 2) Computer program BATYR (Automated analysis of words and text). Certificate of state registration of the computer program No. 2014613238 (M. 2013); 3) Computer program SCHETOVOD (Automated text analysis). Certificate of state registration of computer program No. 2014618598 (M. 2014); 4) Computer program PULSE 2015 for processing the rhythm of prose text. Certificate of state registration of the computer program No. 2015614549 (Moscow, 2015); 5) Computer program BYURGER (Automated analysis of words and text). Certificate of state registration of the computer program No. 2016616320 (Moscow, 2016).

\section{Findings}

With the help of lexical, grammatical, and stylistic means, a negative picture is formed in the mind of the addressee and a corrupt and submissive image of the Organization as a whole and its Head in particular is built. The identified units of different levels of language create the semantic basis of the communicative space of the social network, which is clarified through comments, evaluations, etc. The meaning of the word includes not only the conceptual core, which allows you to distinguish this subject from a number of others, but also the figurative-sensory representation, and emotionalevaluative and stylistic meanings. The combination of these creates certain stylistic effects that give the caricature one or another tonality, which expresses the sarcastic attitude of the author to the unsub and the subject of the image.

6.1 In the context of these examples, the significance of the PL paradigm in expert researchs of conflictogenic discourse becomes self-evident. At the same time, it should be noted that the linguistic evaluation significantly complements the analysis, giving the expertise the status of a complex one. Without a competent linguistic component, the logic of describing the material is lost, since psycholinguistics acts as a different, not traditional, methodological platform designed to identify new units of analysis, describe the laws of action and impact of verbal models, as well as formalize the suggestive resources of the products of speech activity. The theoretical basis of the paradigm, laid down by the works of A. A. Leontiev, E. F. Tarasov, A. A. Zalevskaya, N. V. Chernigovskaya, I. N. Gorelova, N. O. Zolotova, S. V. Lebedeva allows you to build a flexible algorithm for analytical and experimental work of detecting and decoding the influencing resources of verbal models of different complexity.

6.2 A fundamentally important point in working on materials in PL format is an objective evaluation, implemented through quantitative indicators, through the established quality of impact, which is also decoded by ranking patterns of rhythmic activity of the brain, combinations of emotional and evaluative signs, explication of the motives and intentions of the author of the text, patterns of sound-color associative color of the verbal model, and today, the establishment of psychoemotional states of the author of the text, its readers or viewers, if we are dealing with video text.

\section{Conclusion}

Since psycholinguistics can be called experimental linguistics, which studies the products of human speech activity, all the formalized data obtained, all the indicators and coefficients can be repeatedly rechecked. Moreover, within the framework of one research, we double-check our results obtained with the help of different tools developed by us, which allow us to consider one problem from different sides.

The linguist in the research proceeds from the principles of ethics of the writer / draughtsman, who in his professional and speech activities is obliged to respect the dignity and honor of the subject / object of his attention: The Artist is always able to adequately, according to the stylistic and ethical norms of the chosen genre of creativity, choose from the means provided by the language that do not discredit the subject of the description. Caricatures and their accompanying texts have a specific character, which, except for some, do not formally have an indecent form, but they are linguosemiotically qualified as being outside the norms of literary language and speech behavior in general, 
which are considered by society as unacceptable in public use.

Taking into account the "conflictogenic risks", experts analyze the speech act from the point of view of the explicit and hidden content of the text, describe the factors that generate the statement and the reaction to it. Knowing the patterns of speech communication, expertsphilologists characterize a specific communicative conflict, and lawyers give the results of the research a legal interpretation. Being an objective study, LE and PLE expertises are not just a complex procedure used to identify speech crimes in the journalistic sphere of communication, but an applied direction that reveals new properties of the conflictogenic media space.

\section{References}

1.E.A. Salikhova, Political Linguistics 3 (81), 198208 (2020)

2.Yu.A. Sorokin, E.F. Tarasov, Optimization of speech impact. (Moscow: High school,1990)

3.E.G. Nikitina, The language of regional television sports reporting and the specifics of its impac. (Izhevsk: Udmurt State University, 2014)

4.A.G. Sonin, D.S. Michurin, Questions of Psycholinguistics 2 (16), 164-174 (2012)

5. T. F. Petrenko, University readings (Pyatigorsk: PSLU. 2015)

6.Z.I. Trubina, Crede Experto: Transport, Society, Education, Language 3, 163-174 (2019).

7. Dictionary of Russian words Dictinary.ru. URL: https://www.dictinary.ru/определение\% 020 слова/напёрс точник.html (date of access: 16.03.20).

8. Large explanatory dictionary of the Russian language (BTSRYaz, Saint Petersburg: Norint, 2007)

9.I.A. Sternin, L.G. Antonova, D.L. Karpov, M.V. Shamanova, Identification of signs of humiliation of honor, dignity, belittling of business reputation and insults in the linguistic expertise of the text (Yaroslavl: Yaroslavl State University, 2013)

10. T. Rogoznikova, Current issues of linguistics and didactics: The interdisciplinary approach in humanities (CILDIAHSS-2018). URL: https://doi.org/10.1051/shsconf/ 20185001146. (date of access: 16.03.20).

11. Culture of Russian speech: An encyclopedic dictionary-reference (Moscow: Flinta-Nauka, 2007)

12. The price of a word (Moscow: Gallery, 2002)

13. E.S. Kara-Murza, Political Linguistics 1(27), 47-71 (2009)

14. A. Ustinov, Domestic notes 6(63) (2014), URL: http://www.strana-oz.ru/2014/6/oskorblenie-kakhudozhestvennyy-zhest. (date of access: 16.03.20).

15. V.I. Shalak, M.N. Dymshits, Software product. The psycholinguistic expert system (VAAL. Moscow, 2005)

16. I.Yu. Cherepanova, Verbal suggestion: theory, methodology, and socio-linguistic experiment (Perm: Perm State University, 1996)

17. Program for the expertise of suggestion texts DIATON, version of SLOVODEL Laboratory "Vedium".
Certificate of state registration for the computer program. No. 2008611081. (Moscow, 2008)

18. T.M. Rogozhnikova, (2017) Proceedings of the 7th International Scientific and Practical Conference "Current issues of linguistics and didactics: The interdisciplinary approach in humanities» Advances in Social Science, Education and Humanities Research (ASSEHR) 97 (2017)

19. T.M. Rogozhnikova, E. A. Salikhova, Eurasian Advocacy 1 (37), 26-38 (2019) 